\title{
Majoring in nutrition influences BMI of female college students
}

\author{
Mee Young Hong*, Tahirih L. Shepanski and Jaclyn B. Gaylis \\ School of Exercise and Nutritional Sciences, San Diego State University, San Diego, CA 92182, USA \\ (Received 17 October 2014 - Final revision received 17 August 2015 - Accepted 1 September 2015)
}

Journal of Nutritional Science (2016), vol. 5, e8, page 1 of 7

doi: $10.1017 /$ jns. 2015.24

Abstract

Maintaining healthy eating habits in college is challenging. Interventions focused on nutrition education can assist in reversing these trends of poor eating habits among college students. The purpose of the study was to identify factors affecting the dietary habits, food choices and BMI of college females majoring in nutrition (NMs) compared with non-nutrition majors (OMs). A questionnaire-based cross-sectional survey study of dietary behaviour and food frequency of 202 college females was conducted at San Diego State University. Data were analysed by using $t$ tests, $\chi^{2}$ tests and regression analysis in SPSS. NMs exhibited a lower BMI than OMs $(P<0 \cdot 01)$; however, BMI values for both groups were within a healthy range. Interestingly, $3 \%$ of NMs had a BMI in the range of overweight or obese; however, prevalence was three times higher for OMs, being $9 \cdot 2 \%$. A healthier meal option was the most influential factor in NMs' meal choices whereas convenience and weight control were influential factors in OMs' meal choices. Most NMs read nutrition labels and reported that this affects their food choices. NMs exercised longer than OMs in the $<120 \mathrm{~min} /$ week category. Exercise affected healthy meal conception in NMs only $(P<0 \cdot 001)$. Taking dietary supplements influenced healthy meal awareness in OMs only $(P<0 \cdot 05)$. University-level nutrition education is strongly associated with healthier eating habits and superior food choices among young adult females. More regular meal patterns, healthier snack choice and adherence to dietary guidelines may contribute to the lower BMI values observed among NMs compared with OMs.

Key words: College students: Majoring in nutrition: BMI: Dietary habits: Health behaviour

Nutritional intake during young adulthood supports physical health, affects risk for future disease and plays a role in the prevention of excess weight gain. The lack of variety in college students' food choices were revealed in data from the 2012 American College Health Association-National College Health Assessment (ACHA-NCHA), where only 5.3\% consumed the recommended daily intake of fruit and vegetables and most ate diets excessive in fat ${ }^{(1,2)}$. Dietary intake low in fruits and vegetables while high in refined carbohydrates and fats is closely linked to one's BMI and directly correlates with the risk of chronic disease in late adulthood ${ }^{(3,4)}$.

Statistics from San Diego State University's (SDSU) campus 'Quick Serve Restaurants' demonstrate students' high consumption of unhealthy food and low consumption of healthier items. In January 2013, 8607 out of 38495 students purchased à la carte French fries; that increased by $11 \%$ to 12817 total purchases in 2014 at SDSU's Towers Kitchen ${ }^{(5)}$. The sale of vegetable dishes dropped from 1580 in 2013 to 666 in $2014^{(5)}$. Given that poor dietary intake is one of the leading modifiable contributors to mortality, nutrition promotion among developing adults is an important focal area for research ${ }^{(6)}$.

National data also reveal that physical activity levels drop dramatically between junior high school and college graduation $^{(7)}$. According to the ACHA-NCHA, only $19.5 \%$ of college students engage in physical activity five or more days per week, with $25 \cdot 2 \%$ reporting zero physical activity in the last $7 \mathrm{~d}^{(2)}$. Additionally, in this demographic, there is a higher prevalence of dieting behaviours among college women who avoid gaining body fat, have lower self-esteem, and are preoccupied with body size and shape ${ }^{(8)}$.

Abbreviations: NMs, nutrition major students; OMs, non-nutrition major students; SDSU, San Diego State University.

* Corresponding author: Dr M. Y. Hong, fax +1 619594 6553, email mhong2@mail.sdsu.edu

(C) The Author(s) 2016. This is an Open Access article, distributed under the terms of the Creative Commons Attribution licence (http:// creativecommons.org/licenses/by/4.0/), which permits unrestricted re-use, distribution, and reproduction in any medium, provided the original work is properly cited. 
Research shows that college students gain an average of $3.5 \mathrm{~kg}$ during their freshman year ${ }^{(9)}$. In order to reverse unhealthy eating habits that may lead to obesity, researchers have used nutrition education interventions among college students $^{(4)}$. When comparing the BMI of freshmen that took a nutrition class $v$. those who did not, students with a high $\mathrm{BMI}$ who did not enrol in the nutrition class gained an average of 15 to 20 pounds ( 7 to $9 \mathrm{~kg}$ ) over the 16 -month period ${ }^{(10)}$.

Nutrition education during college years is vital in order to teach college students how to make healthy dietary and lifestyle choices which may affect their overall health and wellbeing.

Nutrition majors (NMs) not only have education on nutrition, food choices, dietary behaviour and diseases but also food preparation and exercise physiology. It is often assumed that NMs make better food choices and lead healthy lifestyles. However, the effectiveness of college nutrition courses on the habits of NMs in correlation with students' BMI, snack choices, food habits and exercise patterns has not been well investigated. The objective of this study was to identify factors that affect the dietary habits and food choices of NMs and non-nutrition major students (OMs). We hypothesised that this formal education in nutrition would positively affect behaviours such as food choice and meal decisions, exercise and sleep patterns, and a healthy body image, which would demonstrate a measurable clinical outcome of a lower BMI in NMs compared with their non-biological-science peers.

\section{Experimental methods}

\section{Subjects and environment}

The study protocol was approved by the Institutional Review Board for research involving human subjects. The objective of this study was to identify factors affecting the dietary habits and food choices of NM compared with OM college female students. A total of 202 subjects (101 female NMs and 101 female OMs) volunteered to complete a survey. Inclusion criteria for a nutrition student was a course major in foods and nutrition while inclusion criteria for a non-nutrition student was any non-biological science or non-healthcare major such as language arts, business, psychology, etc. Exclusion criteria for both groups included: (a) biological science-based majors such as biology, chemistry and nursing as well as public health; (b) foreign exchange students or persons whose residency in the USA was less than 3 years; and (c) male students.

Surveys were completed by NMs in Exercise and Nutritional Science classes while OMs completed surveys in common areas on campus such as bookstores, residence halls and the library. Participants were provided an incentive equivalent to less than 1 US dollar after completing the survey. All participants were 18 years of age or older and provided informed consent at the time of the survey.

\section{Questionnaires}

Questions regarding demographics consisted of age, height, weight, ethnicity, birthplace and duration in the USA. Respondents self-reported their anthropometric measurements. BMI was calculated as weight in $\mathrm{kg}$ divided by the square of height in $\mathrm{m}$. The BMI of the subjects were compared with standards for BMI categorisation: $<18.5 \mathrm{~kg} / \mathrm{m}^{2}=$ underweight; 18.5 to $24.9 \mathrm{~kg} / \mathrm{m}^{2}=$ normal; $\geq 25 \cdot 0 \mathrm{~kg} / \mathrm{m}^{2}=$ overweight/obese. Lifestyle pattern questions included topics such as dietary habits, health concerns, sleep patterns, exercise regimens, stress levels, body image and potential disordered eating. Subjects were also asked questions regarding nutrition knowledge such as nutritional labelling, sources of nutrition information and adherence to published dietary guidelines ${ }^{(11)}$. An FFQ asked how often subjects consumed certain food items: grains, starches, meats, fish, fruits, vegetables, dairy products and beverages including alcohol. The nine potential frequency choices ranged from three times per $d$ to never ${ }^{(12,13)}$.

\section{Statistical analyses}

Data were analysed using SPSS (version 20; IBM Inc.). Q-Q plots for each of the dependent variables were carried out to test normality. Student's $t$ tests with a Bonferroni adjustment were used to analyse the age, weight, height, BMI and lifestyle questions with numerical values. We used $\chi^{2}$ tests to examine differences with categorical variables, such as food frequency, dietary intake and the majority of the lifestyle questions. Correlations among variables were tested using Pearson correlation or Spearman's $\rho$ analysis. Regression analysis was conducted to identify factors affecting self-reported healthy meals. Data are presented as means and standard deviations and statistical significance was set at $P \leq 0 \cdot 05$.

\section{Results}

\section{Demographics}

Subjects included $101 \mathrm{NMs}$ and $101 \mathrm{OMs}$ and the participants' mean age was 23 years. Based on the standards for BMI, $6 \%$ of the subjects were underweight $(\mathrm{BMI}<18.5$ $\mathrm{kg} / \mathrm{m}^{2}$ ), $88 \%$ were normal weight (BMI 18.5 to $24.9 \mathrm{~kg} / \mathrm{m}^{2}$ ) and $6 \%$ were overweight/obese $\quad\left(B M I \geq 25.0 \mathrm{~kg} / \mathrm{m}^{2}\right.$ (Table 1). BMI was significantly different between the two groups; NMs exhibited a lower BMI than OMs $(P=0 \cdot 005)$. Only $3 \%$ of NMs had a BMI in the range of overweight or obese, where it was three times higher being $9.2 \%$ for OMs (Table 1). However, mean BMI values for both groups were within a healthy range. Of the subjects, $79 \%$ identified their ethnicity as white, $9 \%$ as Hispanic, $6 \%$ as other, $4 \%$ as Asian and $2 \%$ as black (Table 1).

\section{Lifestyle habits and health practices}

In this sample of female college students, $88 \%$ were nonsmokers and $73 \%$ reported drinking alcohol one to three times per month (Table 2). There was no difference between NMs and OMs on smoking and drinking habits. Mean length of sleep was significantly different between groups $(\mathrm{NMs}=7 \cdot 2$ (SD 1.1) h; OMs $=6.7(\mathrm{SD} \mathrm{1.8)} \mathrm{h;P=0.001).} \mathrm{Of} \mathrm{the} \mathrm{subjects,}$ $69 \%$ answered that they have sufficient sleep to recover from fatigue but $31 \%$ feel not sufficient; $52 \%$ of subjects 
Table 1. Characteristics of participating female college students (Mean values and standard deviations or percentages)

\begin{tabular}{|c|c|c|c|c|}
\hline & \multicolumn{2}{|c|}{ NMs $\left(\begin{array}{ll}n & 101\end{array}\right)$} & \multicolumn{2}{|c|}{ OMs (n 101) } \\
\hline & Mean & SD & Mean & SD \\
\hline Age (years) & $24 \cdot 3$ & 3.9 & $22 \cdot 4$ & 4.0 \\
\hline Weight (kg) & 58.8 & 7.4 & $60 \cdot 3$ & 9.1 \\
\hline Height $(\mathrm{cm})$ & 166.4 & $6 \cdot 6$ & $166 \cdot 0$ & 7.5 \\
\hline BMI $\left(\mathrm{kg} / \mathrm{m}^{2}\right)^{*}$ & $21 \cdot 2$ & $2 \cdot 0$ & $21 \cdot 3$ & 3.1 \\
\hline \multicolumn{5}{|l|}{ BMI classification (\%)† } \\
\hline Underweight & \multicolumn{2}{|c|}{5.9} & \multicolumn{2}{|c|}{$6 \cdot 1$} \\
\hline Normal & \multicolumn{2}{|c|}{91.1} & \multicolumn{2}{|c|}{84.7} \\
\hline Overweight/obese & \multicolumn{2}{|c|}{$3 \cdot 0$} & \multicolumn{2}{|c|}{$9 \cdot 2$} \\
\hline \multicolumn{5}{|l|}{ Ethnicity (\%) } \\
\hline White & \multicolumn{2}{|c|}{$77 \cdot 2$} & \multicolumn{2}{|c|}{$81 \cdot 2$} \\
\hline Black & \multicolumn{2}{|c|}{$2 \cdot 0$} & \multicolumn{2}{|c|}{$2 \cdot 0$} \\
\hline Hispanic & \multicolumn{2}{|c|}{$12 \cdot 9$} & \multicolumn{2}{|c|}{5.9} \\
\hline Asian & \multirow{2}{*}{\multicolumn{2}{|c|}{$\begin{array}{l}1.0 \\
6.9\end{array}$}} & \multicolumn{2}{|c|}{$5 \cdot 9$} \\
\hline Other & & & \multicolumn{2}{|c|}{5.0} \\
\hline
\end{tabular}

NMs, nutrition major students; OMs, non-nutrition major students.

* Mean values were significantly different between NMs and OMs $(P<0.05, n 202$; non-paired $t$ tests).

†BMI classification: $<18.5 \mathrm{~kg} / \mathrm{m}^{2}=$ underweight; 18.5 to $24.9 \mathrm{~kg} / \mathrm{m}^{2}=$ normal; $>25.0 \mathrm{~kg} / \mathrm{m}^{2}=$ overweight/obese.

Table 2. Female college students' lifestyle habits and health practices (\%)

\begin{tabular}{|c|c|c|c|}
\hline & NMs $(n$ 101) & OMs (n 101) & Overall \\
\hline No smoking & 91 & 84 & 88 \\
\hline Alcohol drinking & 70 & 76 & 73 \\
\hline Sleep sufficient & 69 & 68 & 69 \\
\hline \multicolumn{4}{|l|}{ Stress } \\
\hline Slight & 52 & 52 & 52 \\
\hline Very & 45 & 52 & 44 \\
\hline Try to lose body weight & 48 & 53 & 51 \\
\hline To improve health & 45 & 40 & 42 \\
\hline To look better & 52 & 53 & 53 \\
\hline \multicolumn{4}{|c|}{ How to control body weight } \\
\hline Diet control* & 20 & 11 & 16 \\
\hline Exercise* $^{\star}$ & 35 & 58 & 47 \\
\hline Both* & 40 & 22 & 31 \\
\hline
\end{tabular}

NMs, nutrition major students; OMs, non-nutrition major students.

* NMs mainly changed their dietary and exercise habits while OMs mainly focused on enhancing their exercise $\left(P<0.05, n 202 ; \chi^{2}\right.$ test).

reported feeling 'slightly stressed' while $44 \%$ reported feeling 'very stressed'. Overall, more than $90 \%$ cited school and family as the reasons for stress.

About $51 \%$ of subjects had tried to lose weight (Table 2). Of the subjects, $53 \%$ cited the reason for weight control 'to look better' while $42 \%$ cited wanting 'to improve health'. Both NMs and OMs focused on exercise and/or changing their dietary habits when trying to control their weight. However, NMs mainly changed their dietary and exercise habits while OMs mainly focused on enhancing their exercise $(P<0 \cdot 05)$ (Table 2). There were no differences between NMs and $\mathrm{OMs}$ on the questions regarding disordered eating or potential eating disorder.

Of the subjects, $70 \%$ reported exercising 'regularly' during the previous month. NMs reported exercising $3.24 \mathrm{~d} /$ week with a mean of $62 \mathrm{~min} / \mathrm{d}$ (Table 3). OMs exercised $3.07 \mathrm{~d} /$ week with a mean of $58 \mathrm{~min} / \mathrm{d}$. No statistical difference was found between NMs and OMs on exercise frequency and duration. Yet, out of the NMs and OMs who exercise under the recommended $120 \mathrm{~min} /$ week, NMs recorded an average $26.1 \mathrm{~min} /$ week $v$. OMs at $7.2 \mathrm{~min} /$ week $(P=0.032)$ (Table 3$)$.

\section{Dietary habits and meal factors}

Of all subjects, $19 \%$ reported skipping breakfast; however, $87 \%$ of NMs reported eating breakfast in the $2 \mathrm{~d}$ prior compared with $75 \%$ of OMs $(P=0.036)$ (Fig. 1(a)). In all, $55 \%$ of all subjects snacked two times per $\mathrm{d}$ and $32 \%$ of all subjects reported snacking on fruit and fruit juice (44\% NMs $v .20 \%$ OMs) $(P=0.040)$; however, $14 \%$ of OMs and $5 \%$ of NMs reported snacking on cookies and chips (crisps) $(P=0 \cdot 042)$. Fig. 1(b) presents significant differences between groups regarding influential factors in meals. Of NMs, $55 \%$ reported nutritionally great meals $v .32 \%$ of OMs reporting great meals $(P<0 \cdot 001)$. A healthier meal option was the most influencing factor in $69 \%$ of $\mathrm{NMs}$ ' meal choices while convenience $(28 \%)$ and weight control $(22 \%)$ as well as a healthier meal were the major influential factors in $\mathrm{OMs}^{\prime}$ meal choices $(P<0 \cdot 05)$.

\section{Sources of nutrition knowledge}

Of NMs, $99 \%$ reported that they read nutritional labels compared with $83 \%$ of OMs $(P<0 \cdot 001)$ (Fig. 2(a)). Additionally, $98 \%$ of NMs $v .85 \%$ of OMs reported that label reading 'affects' their food choices $(P=0 \cdot 001)$. About $42 \%$ of OMs read labels because they were interested in the total energy while only $24 \%$ of NMs read labels for this reason $(P=$ $0 \cdot 021)$. NMs $(14 \%)$ reported being interested in the fat content on labels compared with only $2 \%$ of OMs.

The media (television/Internet/news/books/magazines) were cited as a primary source of nutritional information for $45 \%$ of $\mathrm{OMs}$ while $58 \%$ of $\mathrm{NMs}$ cited group instruction $(P<0.001)$ (Fig. 2(b)). Additionally, $34 \%$ of OMs received nutritional information from friends and family while only $1 \%$ of NMs cited this source.

\section{Adherence to Dietary Guidelines for Americans}

Subjects were presented with the Dietary Guidelines for Americans and were asked to determine whether they: (a) 'practise well', (b) 'try to practise', or (c) 'don't practise' each of the seven guidelines (Table 4). Results show that $60 \%$ of NMs reported 'well' when eating a variety of foods, while $54 \%$ of OMs reported that they 'try' $(P<0 \cdot 001)$. When balancing food with physical activity to maintain or lose weight, $50 \%$ of NMs reported doing this 'well' while $56 \%$ of OMs reported that they 'try' $(P=0.041)$. More than $62 \%$ of NMs reported choosing plenty of grains, vegetables and fruits and limited their dietary fat 'well' while $55 \%$ of OMs reported that they 'try' $(P<0.001)$. About $37-39 \%$ of NMs reported limiting their sugars and salt 'well' while $23-29 \%$ of OMs reported that they 'don't practise' $(P<0.001)$. Last, $53 \%$ of $\mathrm{NMs}$ reported drinking alcohol in moderation 'well' while $45 \%$ of OMs reported that they 'try'. 
Table 3. Female college students' exercise frequency and duration (Mean values and standard deviations or percentages)

\begin{tabular}{|c|c|c|c|c|c|c|c|}
\hline & \multicolumn{2}{|c|}{ NMs $(n$ 101) } & \multicolumn{2}{|c|}{ OMs $(n 101)$} & \multicolumn{3}{|c|}{ Overall } \\
\hline & Mean & SD & Mean & SD & Mean & & SD \\
\hline Exercise (d/week) & 3.24 & 1.91 & 3.07 & 1.90 & 3.15 & & 1.91 \\
\hline Exercise $(\mathrm{min} / \mathrm{d})$ & 62.3 & 37.7 & $58 \cdot 0$ & $40 \cdot 8$ & $60 \cdot 2$ & & $39 \cdot 3$ \\
\hline Exercise (min/week) & 240 & 189 & 212 & 208 & 226 & & 199 \\
\hline$<120 \mathrm{~min} /$ week (min/week)* & $26 \cdot 1$ & 37.6 & $7 \cdot 2$ & $16 \cdot 6$ & $16 \cdot 7$ & & $26.9(28)$ \\
\hline Percentage & & & & & & 28 & \\
\hline 120-210 $\mathrm{min} /$ week ( $\mathrm{min} /$ week) & $187 \cdot 6$ & $93.0(33)$ & $176 \cdot 0$ & $77 \cdot 8$ & 181.8 & & 93.0 \\
\hline Percentage & & & & & & 30 & \\
\hline$>210 \mathrm{~min} /$ week $(\mathrm{min} /$ week) & $388 \cdot 2$ & 93.0 & $397 \cdot 6$ & $80 \cdot 9$ & 392.9 & & $93 \cdot 0$ \\
\hline Percentage & & & & & & 42 & \\
\hline
\end{tabular}

NMs, nutrition major students; OMs, non-nutrition major students.

${ }^{*}$ NMs recorded higher average exercise time compared with OMs in the category of $<120 \mathrm{~min} /$ week $(P<0.05, n 202$; non-paired $t$ tests $)$.
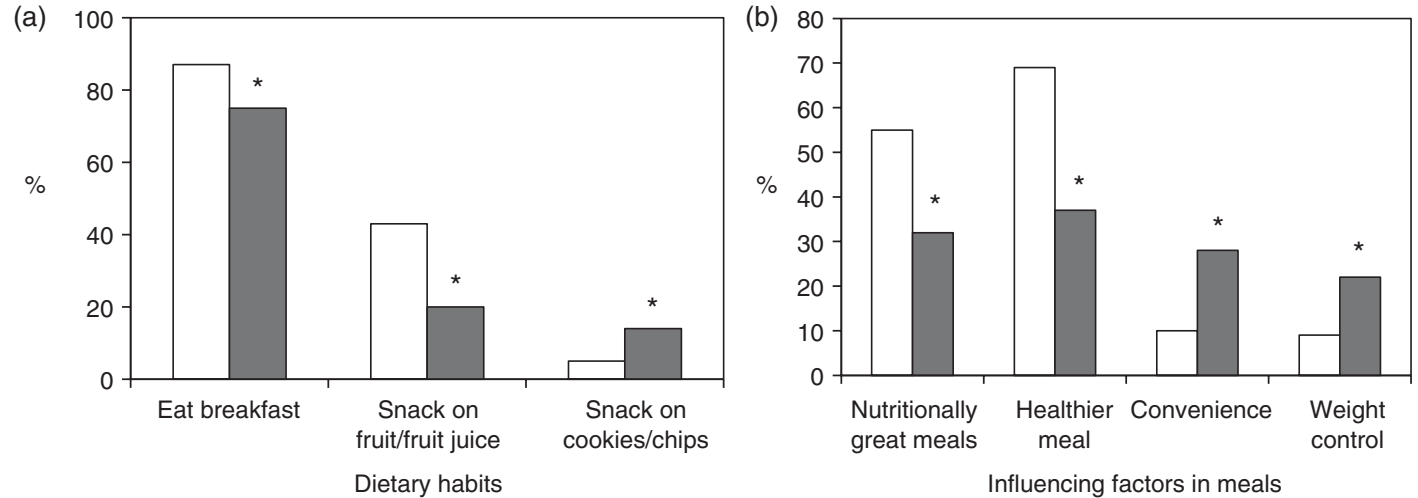

Fig. 1. (a) Dietary habits on breakfast eating and snack choices between nutrition major students (NMs; $\square$ ) and non-nutrition major students (OMs; factors in meals between NMs and OMs. ${ }^{*} P<0.05$ ( $n$ 202; $\chi^{2}$ analysis). Values are percentages.

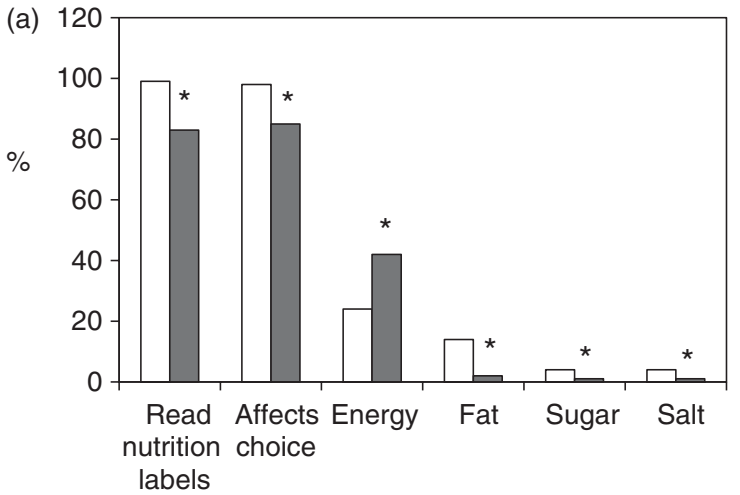

Nutrition labels

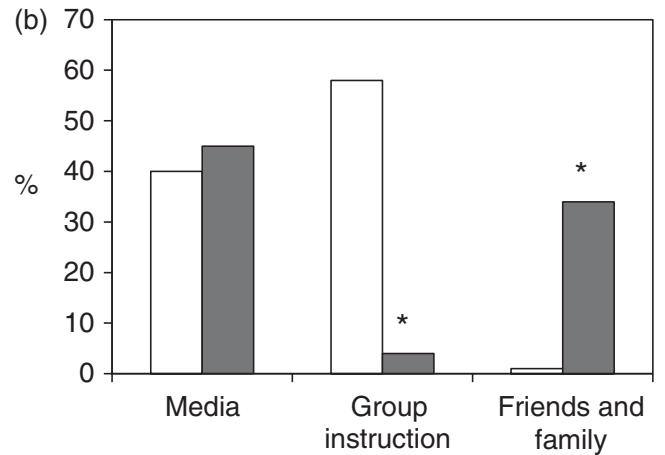

Sources of nutrition information

Fig. 2. (a) Nutritional label reading between nutrition major students (NMs; $\square$ ) and non-nutrition major students (OMs; $\mathbf{})$. (b) Source of nutrition information between NMs and OMs. ${ }^{*} P<0.05$ ( $n$ 202; $\chi^{2}$ analysis). Values are percentages.

\section{Correlations}

The correlation between certain health behaviours and BMI demonstrates that healthy habits tend to result in a lower BMI (Table 5). There was a strong positive correlation between thoughts of 'feeling fat' and a higher BMI (coefficient $r$ 0.629; $P<0.001)$. Students with a higher BMI showed a higher tendency to lose body weight $(P=0 \cdot 029)$. Nutrition label readers had a lower BMI compared with non-readers $(P=0.028)$ (Table 5). Those with a higher BMI also had a lower adherence rate in following the guidelines of eating more fruits and vegetables and consuming a low-fat diet $(P<0 \cdot 05)$. People with a high BMI recorded low salad consumption (coefficient $r-0 \cdot 216 ; P=0 \cdot 014$ ) and high soda consumption $(P=0 \cdot 050)$.

Numerous factors were evaluated to determine whether NMs and OMs considered certain behaviours as having a positive influence and if those factors affected their perception of a 
Table 4. Adherence to Dietary Guidelines for Americans (\%)

\begin{tabular}{|c|c|c|c|c|}
\hline Guideline & Practise? & $\begin{array}{l}\text { NMs } \\
(n \text { 101) }\end{array}$ & $\begin{array}{l}\text { OMs } \\
(n 101)\end{array}$ & $P^{\star}$ \\
\hline \multirow[t]{3}{*}{ Eat a variety of foods } & Well & $60 \cdot 4$ & $36 \cdot 6$ & \\
\hline & Try & 39.6 & 53.5 & $<0.001$ \\
\hline & Don't & 0.0 & 9.9 & \\
\hline \multirow{3}{*}{$\begin{array}{l}\text { Balance food and } \\
\text { physical activity }\end{array}$} & Well & 49.5 & $32 \cdot 7$ & \\
\hline & Try & $44 \cdot 6$ & $56 \cdot 4$ & 0.041 \\
\hline & Don't & 5.9 & 10.9 & \\
\hline \multirow{3}{*}{$\begin{array}{l}\text { Choose plenty of grains, } \\
\text { vegetables and fruit }\end{array}$} & Well & 73.0 & $37 \cdot 6$ & \\
\hline & Try & $26 \cdot 0$ & 54.5 & $<0.001$ \\
\hline & Don't & 1.0 & 7.9 & \\
\hline \multirow{3}{*}{$\begin{array}{l}\text { Choose diet low in fat, } \\
\text { saturated fat and } \\
\text { cholesterol }\end{array}$} & Well & 62.4 & $26 \cdot 7$ & \\
\hline & Try & 34.7 & 59.4 & $<0.001$ \\
\hline & Don't & 3.0 & 13.9 & \\
\hline \multirow{3}{*}{$\begin{array}{l}\text { Choose diet moderate in } \\
\text { sugars }\end{array}$} & Well & $36 \cdot 6$ & $20 \cdot 0$ & \\
\hline & Try & 58.4 & $57 \cdot 0$ & $<0.001$ \\
\hline & Don't & $5 \cdot 0$ & $23 \cdot 0$ & \\
\hline \multirow{3}{*}{$\begin{array}{l}\text { Choose diet moderate in } \\
\text { salt and } \mathrm{Na}\end{array}$} & Well & 39.0 & $24 \cdot 0$ & \\
\hline & Try & $49 \cdot 0$ & $47 \cdot 0$ & 0.005 \\
\hline & Don't & $12 \cdot 0$ & 29.0 & \\
\hline \multirow[t]{3}{*}{ Alcohol in moderation } & Well & $52 \cdot 6$ & 37.8 & \\
\hline & Try & 33.0 & 44.9 & 0.110 \\
\hline & Don't & 14.4 & $17 \cdot 3$ & \\
\hline
\end{tabular}

NMs, nutrition major students; OMs, non-nutrition major students.

* NMs mainly changed their dietary and exercise habits while OMs mainly focused on enhancing their exercise $\left(P<0.05, n 202 ; \chi^{2}\right.$ test $)$.

Table 5. Correlation of health behaviours with BMI

\begin{tabular}{lrr}
\hline & Coefficient & \multicolumn{1}{c}{$P^{*}$} \\
\hline Feels fatty & 0.629 & $<0.001$ \\
Try to lose weight & 0.156 & 0.029 \\
Choose grains, fruit and vegetables & -0.178 & 0.012 \\
Choose low fat & -0.169 & 0.017 \\
Salad consumption & -0.216 & 0.014 \\
Soda consumption & 0.173 & 0.050 \\
Read nutrition label & -0.159 & 0.028 \\
\hline
\end{tabular}

* Correlations using Spearman's $\rho$ analyses between certain health behaviours and $\mathrm{BMI}$ demonstrate that healthy habits tend to result in a lower BMI $(P \leq 0.05, n 202)$.

healthy meal (Table 6). Both age and eating breakfast showed a significant difference overall, for both NMs and OMs, which positively affected the value of a healthy meal $(P<0 \cdot 05)$. Adherence to the dietary guidelines, including eating grains, vegetables and fruit, is also significant for both NMs and OMs affecting their perception of a healthy meal $(P<0.05)$. Exercise affected healthy meal conception in NMs only $(P<0 \cdot 001)$. Taking dietary supplements and reading nutrition labels influenced healthy meal awareness in OMs only $(P<0 \cdot 05)$.

\section{Discussion}

This study was designed to compare the dietary habits and food choices of female college NMs and OMs and their relationship with BMI. Our results indicate that NMs have lower
BMI than OMs. A potential reason for this difference is that NMs are more focused on a healthy lifestyle and subsequently read labels more frequently. This practice has a positive effect on their food choices and there is evidence that 'self-regulatory skills', such as reading nutrition labels, positively affect food choices in college students ${ }^{(14)}$. These behaviours related to nutrition provide evidence that factors associated with dietary choices are logical places for knowledge-based interventions. Additionally, our results demonstrate that NMs are more likely to eat breakfast and consume healthier snack options than OMs. These healthier meal patterns may lead to the differences in BMI. This finding is consistent with other research that shows that young people who habitually eat breakfast have better body-weight management and reduced cardiometabolic risk factors compared with those who skip breakfast ${ }^{(15,16)}$. Breakfast skipping induces intense hunger and results in subsequent overeating in heavy, high-fat, highcarbohydrate meals and snacks later in the day. Studies have shown a significant relationship between breakfast skipping and low fruit and vegetable intake among female students ${ }^{(17)}$. Although there is some debate regarding an association with snacking, satiety and energy intake compensation in next meal ${ }^{(18,19)}$, healthy snack consumption should be beneficial to a quality diet and improved health ${ }^{(20)}$. Based on our findings, NMs, with additional formal nutrition, appear to choose healthier foods for their meals regardless of the times of day and frequencies at which they choose to eat.

NMs also look for total energy, energy from fat, $\mathrm{Na}$ and sugar content of the foods. Studies demonstrated that women who received energy information chose significantly lower-energy meals than women who did not receive energy information $^{(21)}$. This practice combined with NMs reporting that they are more likely to 'practise well' six out of seven of the Dietary Guidelines for Americans may lead NMs to choose healthier foods for consumption. Reading the nutrition label in its entirety is essential to help people make the healthiest selection ${ }^{(22)}$. Since NMs study the science of how the human body responds to certain foods, they understand that choosing nutrient-dense foods over low-energy options benefits the body by providing it with nutrients and fuel. Due to their knowledge of nutrient density, NMs will make food choices based on the whole composition of the food, rather than solely on the total amount of energy.

Although the FFQ did not indicate significant differences in food choice between groups, portion sizes were not reported and portion sizes can make a difference in energy intake, which in excess correlates with weight gain ${ }^{(23)}$. Recognition of portion sizes and how to educate others on portion size is part of the university nutrition curriculum so it can be assumed that NMs share experience practising this health behaviour as well. The knowledge of portion control may correlate to the NMs' lower BMI values compared with OMs'.

When evaluating certain factors that may influence one's perception of a healthy meal, factors such as age, consuming breakfast and adhering to nutrition guidelines are significant independent of being a NM. However, certain factors have varying effects on NMs and OMs. NMs associate exercising with a healthy meal, in contrast to OMs who do not. 
Table 6. Regression on factors affecting perception of a healthy meal ${ }^{\star}$ (Regression coefficients)

\begin{tabular}{|c|c|c|c|c|c|c|}
\hline \multirow[b]{2}{*}{ Variables } & \multicolumn{2}{|c|}{ NMs $(n$ 101) } & \multicolumn{2}{|c|}{ OMs $(n 101)$} & \multicolumn{2}{|c|}{ Overall } \\
\hline & B & $P$ & B & $P$ & B & $P$ \\
\hline Age & 0.056 & $<0.001$ & 0.046 & 0.026 & 0.061 & $<0.001$ \\
\hline Weight & -0.004 & 0.603 & 0.006 & 0.552 & 0.001 & 0.889 \\
\hline Height & 0.005 & 0.609 & 0.016 & 0.163 & 0.012 & 0.124 \\
\hline BMI & 0.033 & 0.284 & 0.033 & 0.923 & 0.024 & 0.245 \\
\hline Exercise time ${ }^{\star}$ & 0.001 & $<0.001$ & 0.000 & 0.494 & 0.001 & 0.003 \\
\hline Eating breakfast & 0.448 & 0.013 & 0.698 & $<0.001$ & 0.661 & $<0.001$ \\
\hline Dietary supplement ${ }^{*}$ & 0.059 & 0.161 & 0.194 & 0.001 & 0.120 & 0.001 \\
\hline Read nutrition label ${ }^{*}$ & 0.690 & 0.267 & 0.542 & 0.007 & 0.711 & 0.001 \\
\hline \multicolumn{7}{|l|}{ Nutrition guideline } \\
\hline Eat a variety of foods & 0.469 & $<0.001$ & 0.499 & $<0.001$ & 0.599 & $<0.001$ \\
\hline Balance food and physical activity & 0.270 & 0.007 & 0.484 & $<0.001$ & 0.433 & $<0.001$ \\
\hline Grains, vegetables and fruit & 0.511 & $<0.001$ & 0.544 & $<0.001$ & 0.605 & $<0.001$ \\
\hline Fat, saturated fat and cholesterol & -0.330 & 0.003 & -0.662 & $<0.001$ & -0.580 & $<0.001$ \\
\hline Sugars & -0.350 & 0.001 & -0.551 & $<0.001$ & -0.530 & $<0.001$ \\
\hline Salt and $\mathrm{Na}$ & -0.237 & 0.010 & -0.477 & $<0.001$ & -0.422 & $<0.001$ \\
\hline
\end{tabular}

NMs, nutrition major students; OMs, non-nutrition major students.

${ }^{*}$ Regression analyses indicated that there were some different factors affecting perception of a healthy meal between NMs and OMs $(P<0.05, n 202)$.

Moreover, OMs believed consuming a dietary supplement or reading nutrition labels improved the nutritional value of their meals, while NMs did not find these factors influential. This may be due to the fact that NMs already read nutrition labels and are more focused on regular diets rather than consuming dietary supplements. Discrete regression models to identify factors affecting the perception of a healthy meal between NMs $v$. OMs should be considered.

It is interesting to find that $70 \%$ of NMs and OMs students exercised regularly $(3 \mathrm{~d} /$ week, $60 \mathrm{~min} / \mathrm{d})$. Our study did not find significant differences between the NMs $v$. OMs with regards to exercise regularity, length, or intensity. However, the lower activity group was higher in OMs than NMs. Studies on freshman weight gain during the first year of college indicate that an increase in body weight is, in part, due to decreases in physical activity ${ }^{(24,25)}$. Future studies will include the comparison of exercise activity before, during and after college.

There is conflicting evidence whether nutrition education increases the risk of a potential eating disorder or disordered eating. Some studies show a correlation while other studies indicate that eating disorders or the risk for disordered eating behaviours are not more prevalent among nutrition students when compared with students from other courses ${ }^{(26)}$. The results from our study did not show a correlation between NMs and an increased risk of an eating disorder or disordered eating, as there were no differences between NMs and OMs. Future studies are necessary to investigate this possible association further.

Limitations of this study include the use of a convenience sample for surveying rather than a random sample. In addition, self-reported anthropometric measures were used. Some studies showed that disparities exist when using selfreported anthropometric measures; however, others have demonstrated high validity of self-reported height and weight ${ }^{(27-29)}$. We used BMI to assess relative health and fitness. Even though BMI is a useful way to classify body weight, it may not be the best indicator of health and fitness or chronic disease risk. Body composition, blood analyses and blood pressure may serve as additional indicators of health and fitness in future studies. While FFQ tools are a well-recognised method for dietary assessment in large-scale studies, it can be difficult to accurately estimate serving sizes and food intake. It remains to be determined whether or not the knowledge of portion control correlates with BMI.

\section{Implications for research and practice}

Our study demonstrated that NMs were more likely to adhere to dietary guidelines, establish healthy meal patterns, and use nutritional information to choose healthier foods, which may contribute to their lower BMI values. As lower BMI is associated with decreased risk for chronic disease, our results add credence to the importance of health education for improving the lifelong health of college students. We have observed that nutrition education may improve the dietary and health behaviours of college students and may decrease obesity rates among young adults. Educators in nutrition and exercise play a vital role in helping students develop healthy habits in order to prevent obesity. NMs' positive influence on campus for promoting these benefits may make a significant impact on those outside of their own major. We intend to further explore our findings in a larger cohort involving male and female college students in the future. It is of interest to investigate the different exercise habits and BMI of exercise physiology majors compared with NMs and OMs. Future studies will also include comparing how well students have maintained a healthy lifestyle post-graduation. We are interested to see if students from certain majors have implemented any healthy behaviours that they learned while in university.

\section{Acknowledgements}

The authors acknowledge SDSU NUTR 302L students for their help in data collection. The authors also thank all the 
participants for their time and participation in this study. The contribution of each author was as follows: M. Y. H. designed and conducted the study and advised throughout the project and in manuscript preparation, T. S. drafted the manuscript and J. G. provided help validating the knowledge items and writing the manuscript.

This study received no specific grant from any funding agency, commercial or not-for-profit sectors.

There were no conflicts of interest.

\section{References}

1. Centers for Disease Control and Prevention (2013) The State Indicator Report on Fruits \& Vegetables. http://www.cdc.gov/ nutrition/everyone/fruitsvegetables/index.html (accessed July 2014).

2. American College Health Association (2013) National College Health Assessment II: Fall 2012 Reference Group Data Report. Baltimore, MD: American College Health Association. http://www.acha-ncha.org/ docs/ACHA-NCHA-II_ReferenceGroup_DataReport_Fall2012. pdf (accessed July 2014).

3. Richards A, Kattelmann KK \& Ren C (2006) Motivating 18- to 24-year-olds to increase their fruit and vegetable consumption. J Am Diet Assoc 106, 1405-1411.

4. Bayer O, Nehring I, Bolte G, et al. (2014) Fruit and vegetable consumption and BMI change in primary school-age children: a cohort study. Eur J Clin Nutr 68, 265-270.

5. SDSU (2013) Dining Point of Sale Data. University Towers Kitchen at University Towers (accessed June 2014).

6. Laska MN, Larson NI, Neumark-Sztainer D, et al. (2009) Dietary patterns and home food availability during emerging adulthood: do they differ by living situation? Public Health Nutr 13, 222-228.

7. Wengreen HJ \& Moncur C (2009) Change in diet, physical activity, and body weight among young-adults during the transition from high school to college. Nutr J 8, 32 .

8. Napolitano MA \& Himes S (2011) Race, weight, and correlates of binge eating in female college students. Eat Behav 12, 29-36.

9. Lloyd-Richardson EE, Lucero ML, DiBello JR, et al. (2008) The relationship between alcohol use, eating habits and weight change in college freshmen. Eat Behav 9, 504-508.

10. Matvienko O, Lewis DS \& Schafer E (2001) A college nutrition science course as an intervention to prevent weight gain in female college freshman. J Nutr Educ 33, 95-101.

11. US Department of Health and Human Services and US Department of Agriculture (2005) Dietary Guidelines for Americans, 6th ed. Washington, DC: US Government Printing Office.

12. Na YJ \& Lee SH (2012) Development and validation of a quantitative food frequency questionnaire to assess nutritional status in Korean adults. Nutr Res Pract 6, 444-450.
13. Lee JY, Jun N \& Baik I (2013) Associations between dietary patterns and screen time among Korean adolescents. Nutr Res Pract 7, 330-335.

14. Strong KA, Parks SL, Anderson E, et al. (2008) Weight gain prevention: identifying theory-based targets for health behavior change in young adults. J Am Diet Assoc 108, 1708-1715.

15. Leidy HJ (2013) The benefits of breakfast consumption to combat obesity and diabetes in young people. Am J Lifestyle Med 7, 98-104.

16. Shafiee G, Kelishadi R, Qorbani M, et al. (2013) Association of breakfast intake with cardiometabolic risk factors. J Pediatr 89, 575-582.

17. Lazzeri G, Pammolli A, Azzolini E, et al. (2013) Association between fruits and vegetables intake and frequency of breakfast and snacks consumption: a cross-sectional study. Nutr J 12, 123.

18. Dougkas A, Minihane AM, Givens DI, et al. (2012) Differential effects of dairy snacks on appetite, but not overall energy intake. Br J Nutr 108, 2274-2285.

19. Reas DL, Wisting L, Kapstad H, et al. (2012) Nibbling: frequency and relationship to BMI, pattern of eating, and shape, weight, and eating concerns among university women. Eat Behav 13, 65-66.

20. El Khoury D, Brown P, Smith G, et al. (2014) Increasing the protein to carbohydrate ratio in yogurts consumed as a snack reduces postconsumption glycemia independent of insulin. Clin Nutr 33, 29-38.

21. Bu SY (2013) Transitional changes in energy intake, skeletal muscle content and nutritional behavior in college students during coursework based nutrition education. Clin Nutr Res 2, 125-134.

22. Cannoosamy K, Pugo-Gunsam P \& Jeewon R (2014) Consumer knowledge and attitudes toward nutritional labels. J Nutr Educ Behav 46, 334-340.

23. Kesman RL, Ebbert JO, Harris KI, et al. (2011) Portion control for the treatment of obesity in the primary care setting. BMC Res Notes 4, 346.

24. Hartman JE, ten Hacken NH, Boezen HM, et al. (2013) Selfefficacy for physical activity and insight into its benefits are modifiable factors associated with physical activity in people with COPD: a mixed-methods study. J Physiother 59, 117-124.

25. Smith-Jackson T \& Reel JJ (2012) Freshmen women and the "Freshman 15": perspectives on prevalence and causes of college weight gain. J Am Coll Health 60, 14-20.

26. Poinhos R, Diogo A, Elisee V, et al. (2015) Eating behaviour among undergraduate students. Comparing nutrition students with other courses. Appetite 84, 28-33.

27. Larsen JK, Ouwens M, Engels RC, et al. (2008) Validity of selfreported weight and height and predictors of weight bias in female college students. Appetite 50, 386-389.

28. Bowring AL, Peeters A, Freak-Poli R, et al. (2012) Measuring the accuracy of self-reported height and weight in a community-based sample of young people. BMC Med Res Methodol 12, 175.

29. Gunnare NA, Silliman K \& Morris MN (2013) Accuracy of selfreported weight and role of gender, body mass index, weight satisfaction, weighing behavior, and physical activity among rural college students. Body Image 10, 406-410. 